\title{
MERAWAT NILAI MEMBANGUN KOTA
}

\author{
Amiruddin Akbar Fisu ${ }^{1}$ \\ ${ }^{1}$ Fakultas Teknik Universitas Andi Djemma Palopo \\ Email: amiruddinakbarfisu07@gmail.com
}

\begin{abstract}
ABSTRAK
Idealnya pembangunan suatu wilayah harus berangkat dari nilai luhur dari tujuan pembangunan itu sendiri. Tren pembangunan beberapa kota di Indonesia dilakukan dengan mencoba untuk mengadopsi kota-kota yang dianggap memiliki kisah sukses. Tulisan ini mengajak kita untuk melihat fenomena tren pembangunan kota di Indonesia.
\end{abstract}

Kata kunci: Tren Pembangunan, perencanaan kota, perkotaan, city branding, Indonesia

“Untuk menjadi kota dunia, tidak perlu tepuk tangan dari seluruh penjuru dunia."

\section{Pengantar}

Beberapa tahun lalu saya menghadiri forum bertajuk 'Makassar Menuju Kota Dunia' yang dipromotori oleh Pemerintah Kota Makassar. Pada forum tersebut, dipaparkan rencana pembangunan infrastruktur, upaya menarik investor, cita-cita monorail, dan bagaimana 'ambisi' Makassar agar mendapat perhatian dunia, tidak lupa disebut kota-kota besar sekelas Singapura, Hongkong, dan beberapa kota-kota maju di Eropa sebagai parameter sukses dan pembanding. Pada satu sesi diskusi, saya mengatakan bahwa seberapa pentingkah pandangan dunia terhadap suatu Kota? Bagaimana dengan pandangan masyarakat kota itu sendiri?

\section{Jakarta dan Ambisi Soekarno}

Pada era 60-an, Soekarno memiliki keyakinan bahwa Indonesia harus berperan menjadi bagian penting dunia. Berbagai usaha dilakukan untuk membuktikan hal itu, agar Indonesia dapat dipamerkan dalam forum dunia, seperti saat Jakarta menjadi tuan rumah Asian Games 1962. Soekarno telah membangun banyak gedung mewah di Jakarta. Hotel Indonesia, Kompleks Senayan dan Gelora Bung Karno, Masjid Istiqlal, Taman Impian Jaya Ancol, dan yang paling terkenal, Monumen Nasional berdiri gagah di Ibu Kota. Namun segala pembangunan dari proyek-proyek Soekarno walau dapat membanggakan bangsa Indonesia dan membuatnya percaya akan 
kemampuanya sendiri, nyatanya gagal dalam meperbaiki kehidupan sebagian besar rakyat Jakarta. Menurut Farabi Fakih, (penulis buku Membayangkan Ibu Kota Jakarta di Bawah Soekarno), pada era pembangunan Soekarno, penduduk Jakarta masih banyak yang tinggal di kampung kumuh, drainase kota tak mampu menampung air sehingga menyebabkan banjir, listrik hanya memenuhi 13\% masyarakat kota, air hanya dinikmati $12,5 \%$ penduduk, dan banyak masalah lainnya.

Melalui berbagai gedung-gedung mewah yang sudah didirikan, Soekarno ingin menunjukan kepada dunia hasil yang telah dibuat Indonesia melalui pembangunan ibu kotanya. Soekarno menganggap pembangunan kota Jakarta merupakan bagian dari sebuah proyek nasionalisme yang besar. Namun pada kenyataanya Soekarno membangun kota bukan untuk siapa-siapa di Jakarta, melainkan untuk tamu asing yang datang. Jakarta selayaknya pameran bagi orang asing. Bila dilihat dari dekat, maka akan terlihat ketidakmerataan yang tersembunyi, seperti orang-orang kecil yang hidup di bawah bayang-bayang gedung-gedungnya yang menjulang tinggi.

\section{City Branding, antara latah dan prestasi}

Sebelumnya, mari kita melihat kota-kota yang mungkin oleh kita sudah masuk kategori 'mendunia'. Mari menengok New York, Paris, Seoul, atau mungkin Singapura. Selain letaknya yang memang berada di negara maju, masalah seperti sampah dan sanitasi sudah bukan isu mereka, tidak ada persoalan 'mati lampu', jalan berlubang, macet atau sulitnya memperoleh air bersih di kota mereka. Mereka sudah selesai dengan masalah infrastruktur dasar dan hal-hal yang masih menjadi masalah di negeri ini. Belum lagi infrastruktur transportasi yang juga masih menjadi masalah terutama pada kota=kota besar, salah satunya adalah kurangnya minat masyarakat untuk menggunakan transportasi umum. Menurut Fisu (2016), salah satu ciri kota atau zona yang dapat mempengaruhi pemilihan moda transportasi adalah kepadatan penduduk dan jarak dari pusat kota. Menurut Fisu (2016), radius 400 meter merupakan jarak yang masih tergolong nyaman untuk berjalan kaki.

Mari melihat Kota Penajam di Kabupaten Penajam Paser Utara. Pemerintah daerah kota kelahiran saya ini merencanakan kawasan belasan hektar dengan konsep waterfront city sebagai pusat pemerintahan dan ikon daerah dangan anggaran ratusan milyar. Penerapan konsep waterfront city telah banyak digunakan di kota-kota besar seperti Makassar, Palembang, dan Balikpapan dan dianggap berhasil. Namun di sisi 
lain masih banyak warga yang belum menikmati fasilitas listrik, air bersih dan infrastruktur jalan yang layak dan memadai.

Pada dasarnya, semua kota di Indonesia memiliki karakteristik tersendiri yang dapat dilihat dari kehidupan sosial seperti budaya dan bahasa, hingga karakteristik bangunan dan tata kotanya. Tidaklah buruk mencontoh pembangunan dari sebuah kota yang berhasil. Namun mencopy-paste dan meniru semua yang nampak 'wah' di kota lain adalah hal yang kurang bijak. Belum lepas dari benak kita ketika Dinas Pertamanan Kota Malang yang memasang Fasilitas Gembok Cinta. Niatnya, wahana tersebut menjadi ikon seperti Gembok Cinta di Jembatan Pont Des Invalides, Prancis, sebagai tempat untuk mengabadikan cinta lewat memasang gembok. Namun fasilitas tersebut menuai protes keras dan dianggap 'melegitimasi' anak-anak muda berpacaran dan bertentangan dengan nilai-nilai budaya setempat.

Fenomena lain adalah penggunaan tulisan raksasa untuk menyematkan sebuah atribut modern pada sebuah karya arsitektural. Ini marak terjadi di kota-kota di seluruh Indonesia, tak hanya kota besar, bahkan di beberapa kabupaten latah mengikuti trend ini. Di Anjungan Pantai Losari tiba-tiba muncul tulisan raksasa 'CITY OF MAKASSAR' dan tulisan raksasa lain pada empat anjungannya, di Ibukota Sulbar muncul tulisan 'MAMUJU CITY' ala Hollywood, TAMAN SAMPANGAN di Semarang dan tulisan-tulisan lain yang tersebar di berbagai kota sebagai identitas. Namun untuk apakah furniture tersebut? Apakah fungsi dari tulisan raksasa ini hanya untuk berfoto selfie saja? Inikah hasil dari studi banding yang bolak balik sering dilakukan?

Studi banding bukanlah metode yang buruk untuk melihat contoh-contoh keberhasilan kota atau daerah lain, entah itu di dalam maupun luar negeri. Namun layaknya manusia, kota juga memiliki masalah, potensi, dan karakteristik yang berbeda dengan yang lainnya. Pembangunan kota dengan ambisi membabi buta, rasa haus pengakuan akan keberhasilan, atau dengan serta merta mengcopas keberhasilan kota atau daerah lain hanya akan memunculkan masalah.

\section{Membangun kota, membangun manusia}

Niat dan keinginan untuk membangun, baik itu oleh pemerintah, investor atau pengembang sangat perlu dan penting untuk diapresiasi. Jika kembali kepada nilainilai luhur, perencanaan dan pembangunan yang dilakukan selama ini tentu saja 
dengan tujuan membangun negeri, meningkatkan ekonomi dan mensejahterakan masyarakat.

Lalu kembali pada pertanyaan saya di awal tulisan ini, seberapa pentingkah pandangan dunia terhadap suatu Kota? Bagaimana dengan pandangan masyarakat kota itu sendiri?

Ambisi membangun agar dilihat sebagai daerah yang sukses bukanlah hal yang buruk selama pembangunan tersebut dibarengi dengan azas kebutuhan dan azas manfaat. Pengembangan pariwisata daerah hendaknya menitikberatkan pada lingkungan alami, yakni menjual produk dan pasar yang berdasar dari alam setempat (Ahmad, AA Fisu,, \& Didiharyono, 2019). Membuat citra kota yang eye catching dan mengundang decak kagum para pelancong bukanlah sesuatu yang tidak penting. Namun pembangunan infrastruktur dasar untuk memenuhi kebutuhan masyarakat adalah jauh lebih penting. Belakangan, pada eranya, Soekarno pun mulai membangun infrastruktur pengendali banjir untuk meretas masalah banjir di Ibu Kota.

Lalu apakah tulisan raksasa di Kota-kota Besar itu salah? Apakah mencontoh kota sukses dengan niat meraih kesuksesan yang sama itu tidak boleh? Sah-sah saja, tapi kurang bijak jika serta-merta mengcopas gaya pembangunan dari kota atau daerah lain. Cobalah untuk melihat karakteristik dan budaya daerah serta melibatkan masyarakat di dalam membangun, karena masyarakat bukan hanya sekedar objek atau bagian dari eksperimen dalam pembangunan, namun juga sebagai stakeholder yang memiliki hak dan peran penting dalam pembangunan yang partisipatif. Jika melibatkan masyarakat, berorientasi pada kebutuhan, dan menggunakan skala prioritas, maka inovasi akan mudah diterima dan dipahami maksud dan tujuannya. Banyak contoh kecil copas yang baik, car free day yang awalnya hanya diterapkan di Jakarta, kini menjamur di berbagai daerah dan kota lain. Penerapan konsep smart city pun menjadi trend yang positif dan mulai diterapkan di berbagai kota.

Membangun kota selayaknya juga membangun manusia. Karena peradaban bukan hanya soal gedung dan landmark, tapi juga makhluk yang hidup di dalamnya. Kota seharusnya menjadi ruang yang humanis di tiap sudut dan lekuknya. Bijak dalam membangun, melakukan studi banding ke luar namun tetap menyerap aspirasi dan pendapat masyarakat di dalam. Karena merekalah yang tinggal dan hidup di kota, bukan para pengunjung atau masyarakat dari daerah lain.

“Untuk menjadi kota dunia... tidak perlu tepuk tangan dari seluruh penjuru dunia.... 
Namun diperlukan sebuah masyarakat... yang mengamini kotanya mendunia..."

\section{Daftar Pustaka}

A. Ahmad, A.A. Fisu, dan Didiharyono (2019) Analisis Potensi Ekosistem Mangrove Sebagai Pengembangan Objek Wisata (Studi Kasus: Kabupaten Wakatobi), Prosiding Seminar Nasional UNCP 04 Palopo.

Farabi Fakih (2005) Membayangkan Ibu Kota Jakarta di Bawah Sukarno, Ombak, Yogyakarta

Fisu AA (2016) Potensi Demand pengembangan Kanal Jongaya \& panampu Sebagai Moda Transportasi Kota Makassar, Jurnal JMTranslog Trisakti Vol 03 no 03, Jakarta.

Fisu AA (2016). Analisis dan Konsep Perencanaan Kawasan Pelabuhan Kota Penajam Sebagai Pintu Gerbang Kab. Penajam Paser Utara kalimantan Timur. Jurnal Pena Teknik Vol.1 No.2 2016 (125 - 136) 